\title{
Fast model generation and static calculation of combined pneumatic and mechanically stressed structures
}

\author{
Jürgen Holl*, Dieter Ströbel ${ }^{\dagger}$ \\ * technet $\mathrm{GmbH}$ \\ Pestalozzistraße 8, 70563 Stuttgart, Germany \\ e-mail: juergen.holl@technet-gmbh.com,web page: http://www.technet-gmbh.com \\ $\dagger$ technet $\mathrm{GmbH}$ \\ Pestalozzistraße 8, 70563 Stuttgart, Germany \\ e-mail: dieter.stroebel@technet-gmbh.com, web page: http://www.technet-gmbh.com
}

\begin{abstract}
Computer models have long been essential for the static calculation of membrane or foil structures. In the case of combined pneumatically and mechanically tensioned structures, the generation of the models and the statical calculation is often a challenge.

With pneumatic structures, we are basically dealing with 2 groups: The first group includes the pneumatic structures over an arbitrary boundary. These structures can only be created by a form-finding process considering an internal pressure. The second group includes pneumatically feasible structures like cylinders and spherical segments which are combined to form complete structures. These purely geometrically defined shapes can be created relatively easily by mathematical functions. To keep the manufacturing process simple and production costs low, it is still often seen today that the form-finding process is omitted in case of pneumatically feasible structures.
\end{abstract}

In the case of combinations of pneumatically feasible structures, e.g. tube systems, nurbs geometry is often used. With nurbs, such structures can be easily generated and, above all, intersections between volume geometries can be easily created.

When it comes to combinations of known pneumatically feasible structures together with mechanically stressed parts, it is not possible to completely omit the form-finding process. The mechanically tensioned parts are usually not in force equilibrium after generation via nurbs surfaces. Therefore, in the case of such combined systems, a form finding for the mechanically stressed parts is necessary.

In this article, we show an example of how a pneumatically feasible tube system with mechanically stressed wall elements based on nurbs surfaces can be quickly generated and then statically calculated in our system. For this task, a discrete topologically correct and watertight mechanical model will be generated based on the nurbs model. The user has the possibility to freely choose the mesh size, the material direction and the discretisation of the boundary edges.

Statics starts with the definition of the material properties. In general, we define for textile membranes: warp- and weft stiffness, and, if available, crimp- and shear stiffness. We must fix the internal (operating) pressure values for the chamber(s) and now the non-deformed geometry of the finite membrane elements for the pneumatic and mechanically stressed elements can be calculated. Load case calculations can be performed now by 3 different modes: Constant inner pressure $(\mathrm{p}=$ constant), constant volume $(\mathrm{V}=$ constant), constant product of inner pressure and volume $(\mathrm{p} \cdot \mathrm{V}=$ constant, gas law of Boyle-Mariotte) or even the general gas equation $(\mathrm{p} \cdot \mathrm{V} / \mathrm{T}=$ constant $)$.

We show different load cases (wind, snow) and discuss the application of different calculation modes. 


\section{References}

[1] Ströbel, D., Singer, P., Holl, J. „Analytical Formfinding”, International Journal of Space Structures, Volume: 31 issue: 1, page(s): 52-61, March 1, 2016

[2] Holl, J., Ströbel, D., Singer, P. "Formfinding and Statical Analysis of Cable Nets with flexible covers", VI International Conference on Textile Composites and Inflatable Structures Structural Membranes 2013, Munich, Germany.

[3] Singer, P. (1995), „Die Berechnung von Minimalflächen, Seifenblasen, Membrane und Pneus aus geodätischer Sicht", Dissertationsschrift, DGK Reihe C, Nr. 448, 1995.

[4] Ströbel, D., Holl, J, „On the static calculation of biogas containers with radial and parallel cutting patterns", Structural Membranes 2019, Barcelona, Spain.

[5] Ströbel, D. Singer, P, Holl, J: Holistic Calculation of (Multi)-Chambered ETFE-Cushions, Tensinet, TensiNet Istanbul, 2013.
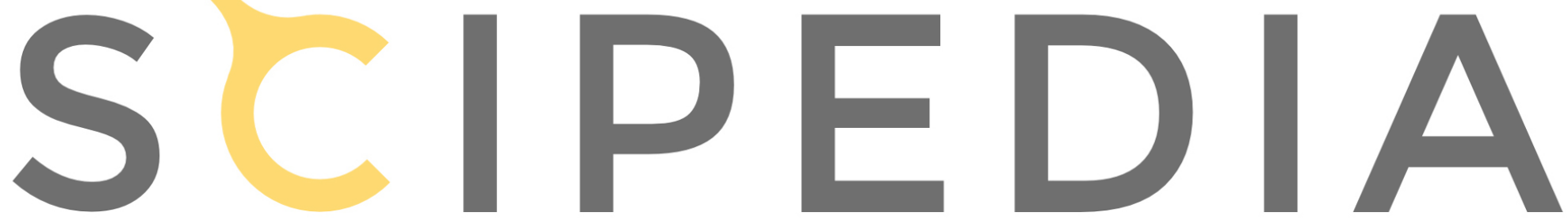